\title{
Assessing the Impact of Regulatory Impact Assessments
}

\author{
Mark Harrison ${ }^{1}$
}

Every political party believes in the idea of better regulation. And yet every political party, once in government, fails to achieve better regulation. ${ }^{2}$

In 1981 President Ronald Reagan's Executive Order 12291 required US Federal agencies to produce a Regulatory Impact Assessment (RIA) for all proposed major regulations - the first attempt to use RIA systematically to improve regulatory outcomes. $^{3}$

An RIA sets out the problem the regulation addresses, the regulation's objectives, different options to achieve them, an assessment of the impacts of each option, and the consultation undertaken, and recommends an option (usually the one with the greatest net benefit). Assessing the impact of each option could include estimating the costs and benefits, measuring business compliance costs, analysing risks and considering the effects on competition. Sometimes the document that details the RIA is called a Regulatory Impact Statement (RIS).

The idea of an RIA is to make regulation more efficient and effective by having its designers justify the reasons for implementing a new regulation, consider the costs and benefits of different options at an early stage and take a community-wide perspective of their effects, to ensure that the benefits to society (broadly conceived) of a regulation are greater than the costs (also broadly conceived) and to encourage the design and adoption of the regulation with the greatest net benefit. 'Ideally, it is used to raise the right questions at the right stages in the policy-making processes with the right people' (Radaelli and Meuwese 2009: 7).

RIAs have proved popular with governments trying (or trying to be seen) to improve the quality of their regulation. By 2005, 26 of 30 OECD countries, and many non-OECD countries, had adopted formal policies mandating the use of RIA in domestic policy-making. ${ }^{4}$ Australia was an early adopter: from 1985 Cabinet required that regulatory proposals with significant effects on business

\footnotetext{
1 Principal, Consultecon, markharrison@ozemail.com.au.

2 Boyfield 2007: 1.

3 See Hahn 2005: 66-7. A major regulation is one with an annual impact of $\$ 100$ million or more Some formal and explicit assessment of the impact of some regulations was undertaken in the US, Finland and Canada in the 1970s, and Denmark had a form of RIA in 1966. See Jacobzone et al. 2007: 35.

4 See Jacobzone, Choi and Miguet 2007: 35, 77-80; Jacob and Associates 2006: 5. The OECD claims in 2005 all member countries routinely carried out some form of RIA on new regulations before finalising and implementing them' (OECD 2008: 6).
} 
include an RIS (Industry Commission 1994: 228). In 1986, the Hawke Government established the Office of Regulation Review (ORR) to encourage good regulatory practice (Industry Commission 1995: 73). Since then, every inquiry in Australia into how to reduce the regulatory burden at the Federal level has recommended strengthening RIA requirements and increasing the ORR's resources and gatekeeper role.

\section{International experience with RIAs}

International studies, however, question whether an RIA process improves regulatory outcomes. Common themes include non-compliance with the regulatory process and poor-quality RIAs.

For example, a US study of the quality of RIAs found agencies failed to comply with RIA requirements. Most agencies failed to quantify costs and benefits, discuss alternatives, use consistent analytical assumptions, report their results clearly or make their results accessible (Hahn et al. 2000; Hahn 2000). A review of New Zealand's regulatory regime also found poor-quality RIAs (Wilkinson 2001: 96).

In a more recent survey, the quality of RIAs in the US was found to fall far short of guidelines and the authors concluded that: '....it does not appear to be getting any better over time. Thus, although there is some evidence economic analysis can improve the benefit-cost ratio of regulations, there is insufficient evidence that economic analysis of regulatory decisions has actually had any substantial impact' (Hahn and Tetlock 2007: 3).

A study of the British RIA process also found the standard of RIAs to be poor, a 'bureaucratic sham', treated as 'as a bolt-on extra designed to justify a regulation' rather than being used to shape and inform policy formulation (Boyfield 2007: 9, 11). There are few incentives for public servants to undertake rigorous RIAs and they often define objectives narrowly, fail to calculate all impacts or consider the effects of non-compliance with the regulation, and resist external scrutiny. Many RIAs actually demonstrate that costs manifestly exceed quantified benefits (Boyfield 2007: 6). The problems are worse if the regulation is politically sensitive.

In their fifth annual report examining UK Government RIAs, Ambling et al. concluded: 'More substantively we question whether RIAs have changed the political reality that ministers introduce regulations because they want them as distinct from being able to justify them. RIAs continue to be used to facilitate regulation rather than challenge the need for it or the quantum' (Ambling et al. 2007: 9).

A study of RIA procedures and practices in the European Union and all Member States found: 
In almost all cases we have examined, there is a large gap between requirements set out in official documents and actual Impact Assessment practice. ...typically assessments are narrow, partial and done at a late stage. In many countries, a large share of proposals is not formally assessed or is assessed with a 'tick box mentality'. ${ }^{5}$

\section{The unintended consequences of dealing with unintended consequences $^{6}$}

In Australia too, the results of RIA requirements have been disappointing. Twenty years after the RIA process was established, the 2006 Taskforce on Reducing Regulatory Burdens on Business pointed out that the 1990s and 2000s saw a dramatic growth in the volume of regulation (Regulation Taskforce 2006: 5). And no-one has detected any improvement in the quality of new regulation. Indeed, complaints about growing regulatory burdens led to the Taskforce inquiry.

It should be no surprise that efforts to improve the quality of regulation may fail. The whole case for regulatory reform is that bureaucrats and politicians have their own interests and objectives and the political process does not automatically lead to policies in the public interest. The pressures and incentives that lead to bad regulation are still present - such as the influence of special interests and populist pressures to 'do something' about the problem of the day. Politicians respond to these pressures. Further, bureaucrats may have their own objectives, such as empire building, which may encourage them to support excessive and inefficient regulations.

Both the regulatory agencies and the central regulatory monitor can lack the incentive to carry out policies to improve the regulatory process.

The focus of regulatory-review inquiries in Australia has been on improving the incentives of regulatory agencies, for good reason: evidence that the RIA requirements are widely ignored. For example, in 1996-97 out of 121 Bills that required the preparation of an RIS, departments only did so in 13 cases, and only 10 (8 per cent) were fully compliant (Industry Commission 1997: 44).

There were no effective sanctions and, thus, low levels of compliance. Even after the RIS requirements were strengthened in March 1997, following the new Howard Government's Bell Review (Bell 1996), the only penalty for non-compliance was to have it pointed out in the ORR's annual report a year later.

\footnotetext{
5 Jacob et al. 2008: 2.

${ }^{6}$ Nick Gruen used this phrase in a Radio National interview to describe the problems with Australia's regulatory process.
} 
Compliance has improved since then, averaging 74 per cent from 1997-2005, indicating that at least some RIAs were being done. But the problems with the RIA process identified in international studies apply in Australia. Compliance has been weaker for the more significant regulations and for the more politically sensitive, and 'In many cases, the RIS is prepared too late in the policy development process to be of any real assistance to decision-makers. In those circumstances, it effectively becomes little more than an ex-post justification for a policy decision already taken, subverting its role' (Banks 2005: 9-10).

In 2006, following the recommendations of the Taskforce on Reducing Regulatory Burdens on Business, the RIA process was again strengthened. A regulatory proposal with medium compliance costs, or significant impacts on business and individuals or the economy, should not proceed to Cabinet or other decision-maker unless it has complied with the regulatory impact-analysis requirements, and non-compliant regulations must have a post-implementation review within two years. These changes increase the incentive for agencies to comply with the RIA process, which was to include more rigorous cost-benefit analysis. The ORR received more resources and had its name changed to the Office of Best Practice Regulation (OBPR).

\section{'Sed quis custodiet ipsos custodes?'}

An issue that has been ignored by the various inquiries is the incentives for the OBPR to perform its role and enforce an RIA process that improves regulation. Yet the OBPR is subject to the same pressures and incentives that lead to bad regulation. As the penalties for non-compliance are raised, the role of the OBPR becomes more important and political pressures become more intense.

The lack of focus on the OBPR's performance has meant the RIA process has often provided it with poor incentives. For example, its main indicator of best practice regulation is the rate at which regulatory bodies comply with the RIA process. Although a low compliance rate from a failure to conduct RIAs indicates the process is being evaded, a high compliance rate tells us little about the quality of the regulatory outcomes. The compliance rate is the number of RIAs judged adequate by the OBPR divided by the number of proposals it says require an RIA. High compliance rates can be produced through low standards of adequacy and requirements.

Many regulations (such as delegated legislation) do not go to Cabinet, and can be passed without OBPR approval. Whether a Department that does so is declared non-compliant depends on OBPR staff detecting regulations that should have been subject to an RIA process. There is not much incentive to declare

\footnotetext{
${ }^{7}$ (Who watches the watchmen?) Juvenal, Satires No.6, 1:347.
} 
regulations that have already been passed as non-compliant, as this could upset the Department and Minister, and potentially embarrass the government.

Not only is it easier (and less work) to declare a regulation compliant with (or exempt from) the RIA process, it is difficult for the conscientious to see any positive results from declaring a passed regulation non-compliant. The only sanction is an increased non-compliant proportion of the Department's regulations in the OBPR Annual Report (a fact which may even be seen to reflect badly on the OBPR and the RIA process if it is in fact noticed by anyone) and, now, a requirement to prepare a post-implementation review (Australian Government 2007: XVIII). But the post-implementation review is to be carried out by the Department that implemented the regulation and is to focus on the way regulation was implemented, rather than on its desirability (Australian Government 2007: 37).

Likewise, life is more difficult for an OBPR officer if an RIS is declared inadequate. Rejections are scrutinised closely; acceptances are not. Pressure on the junior staff can include irate telephone calls to their supervisor from a Departmental Secretary or Minister. The result is the so-called tick-and-flick mentality.

Finally, the greater the OBPR's diligence in tracking down non-compliant regulations, the lower the compliance rate. Yet a high compliance rate is often considered a sign of a successful regulatory process.

\section{'If people don't know what you're doing, then they don't know what you're doing wrong's}

If regulatory proposals need to be accompanied by 'an adequate level of analysis' (Australian Government 2007: 6), what the OBPR considers adequate is crucial. Yet under current arrangements, these decisions lack transparency, making the OBPR less accountable.

For example, it is not clear why no RIA was required for the proposed alcopops tax, despite the explanatory memorandum stating that the tax measure forms 'one part of the Government's ongoing strategy to discourage binge-drinking, particularly among young people' (Parliament of Australia 2009: 6). ${ }^{9}$

Further, there is no provision for post-implementation reviews to be made public, only whether the OBPR judged it adequate.

\footnotetext{
${ }^{8}$ Sir Arnold Robinson, Secretary to the Cabinet in The Complete Yes Minister, Jonathan Lynn and Antony Jay (eds), Harper \& Row, 1988: 21.

${ }^{9}$ The tax took effect on 26 April 2008 (although the Bill to impose the tax increase was later defeated). There is no RIA attached to the explanatory memorandum for the Bill and no mention of it in the 2007-08 OBPR Annual Report, which says an RIA was required for the Tax Law Amendment (Medicare Levy Surcharge Thresholds) Bill 2008 (see Office of Best Practice Regulation 2008: ix, 18).
} 
Some recent evidence on OBPR decisions suggests that if improving the regulatory process is to be more than wishful thinking, the process must take account of, and improve, the incentives and constraints that face decision-makers, including those in the OBPR.

Some researchers recently examined all the risk-related RISs (about half of all RISs) received by the OBPR between December 2004 and September 2008. They found that before the RIA guidelines were strengthened in November 2006 , only 16 per cent of RISs presented estimates of net benefits of the proposed regulations. For those produced after November 2006, the proportion increased to 24 per cent (Austin et al. 2008: 59-60). ${ }^{10}$

Even after the enhanced RIA process was introduced, around three-quarters of risk-related RISs do not provide an estimate of net benefits, despite the Best Practice guidelines of the Australian Government and the Council of Australian Governments (COAG) requiring it. ${ }^{11}$ Yet only a small proportion of completed RISs are declared inadequate. For example, the OBPR reports that for decisions made since the requirements were strengthened and tabled in 2007-08, 51 RISs were required. Three received a Prime Ministerial exemption and 43 were declared compliant, a 90 per cent compliance rate (46/51). What is not made clear, but can be gleaned from the report, is that all the non-compliant cases were because a RIS was not prepared and the regulation went ahead in each case. $^{12}$ All of the completed RISs were declared adequate. ${ }^{13}$

The revelations surrounding the recent FuelWatch proposal exposed the weakness of the current RIA process. The leaked Cabinet documents revealed that four out of five of the Government's economic advisory departments opposed the introduction of the scheme. Even the OBPR's own department (Finance and Deregulation) did not consider 'that the proposed FuelWatch scheme is good practice regulation'. ${ }^{14}$ Yet the OBPR declared the RIS adequate, certifying the proposal as meeting best practice standards (Australian Government 2007: 37). For a regulation to be both 'not good practice' and 'best practice' requires a depressingly pessimistic view about achievable standards of regulation.

The FuelWatch RIS assessed the impacts of four options, but did not estimate the value of costs and benefits or attempt to determine which option had the highest net benefit to the community. Instead, it recommended option 1 (FuelWatch) 'based on its ability to satisfy fully the Government's objectives' (p.15). One and a half pages is spent setting out and estimating option l's business

\footnotetext{
${ }^{10}$ About 60 per cent of the regulatory proposals were received after November 2006 and a little under half were from Council of Australian Governments (COAG) bodies.

11 See Australian Government 2007: 55.

12 See Office of Best Practice Regulation 2008: 18 (Table 2.5), which shows they all require a post-implementation review.

${ }^{13}$ See Office of Best Practice Regulation 2008: 28 (Table 3.2).

14 See, for example, Oakes 2008.
} 
compliance costs as a 'conservative' $\$ 2$ million start-up cost (\$424 per business) and a $\$ 18.7$ million annual ongoing cost $(\$ 3,974$ per business $) .{ }^{15}$

Although the RIA process requires RISs and compliance cost reports to be published with the explanatory memorandum for proposals tabled via Bills, the Treasury did not do so and, instead, replaced the 16-page RIS with a new five-page assessment of the regulation, including four additional objectives. It did not consider different options for achieving the objectives but, instead, asserted that FuelWatch would achieve all of the objectives, and that 'The estimated compliance cost for business is zero' (Parliament of Australia 2008: 2, 6, 8-9). A hard copy of the FuelWatch RIS was lodged with the Tabling Office of the Australian Parliament, apparently meeting the requirement to make it public. Nonetheless, the OBPR declared the Treasury compliant with best practice regulatory process (see Office of Best Practice Regulation 2008: 37).

Although the Best Practice Regulation Handbook (Australian Government 2007) sets out what is required for good regulatory process, it appears that the actual process is far less rigorous, with the OBPR acquiescing in the flouting of its own requirements. It is difficult to discern any benefits from a regulatory process with such low standards or from the OBPR approving an ex-post justification for a decision already made.

\section{Regulating regulation's regulator}

If the RIA process is to be kept, there are a number of practical reforms that could make it more transparent and increase the incentives of all participants to improve the analysis of proposed regulations.

The earlier the RIA process is exposed to public comment and scrutiny, the greater the incentive for decision-makers to genuinely consider regulatory impacts early in the formulation of regulations, and the more likely that the RIA process will improve regulatory decisions. For example, for COAG regulatory proposals, a consultation RIS is produced and sent to the OBPR for comment and then revised before being made public as part of the consultation process. Interested parties can comment on the RIS and it can provide a framework for consultation. The consultation RIS is then revised into an RIS for the decision-maker, which is again reviewed by the OBPR. The regulators and OBPR receive the benefit of comments from stakeholders. A consultation RIS would improve transparency and accountability. So, too, would earlier publication of the final RIS. Currently it is tabled with the regulation in Parliament - too late for many interested parties.

A central register, which the public could access freely on the internet, would also improve transparency. (See Missingham this issue for similar uses of the

15 See Department of the Treasury 2008. 
internet). It should contain RISs for each existing and proposed regulation, as well as the OBPR's reasons for assessing it as compliant or non-compliant. That would increase external scrutiny of the performance of agencies and the OBPR, improving their incentives, and allow interested parties greater participation in the regulatory process. RISs would be easily accessible and different agencies and Departments could be compared. Academics could engage in independent regulatory analysis, including follow-up studies, such as ex-post evaluation of accuracy.

\section{References}

Ambler, T, Chittenden, F. and Deming Xiao 2007, 'The Burden of Regulation: Who is watching out for us?', British Chamber of Commerce, April.

Austin, S., Hartigan, J., Palmer, A., Ritman, F. and Sturges, A. 2008, 'Risk in Regulation: Achieving Better Outcomes', Unpublished Working Paper, Australian New Zealand School of Government.

Australian Government 2007, Best Practice Regulation Handbook, Canberra.

Banks, G. 2005, 'Regulation-making in Australia: Is it broke? How do we fix it?' Public Lecture Series, the Australian Centre of Regulatory Economics (ACORE) and the Faculty of Economics and Commerce, ANU, Canberra, 7 July.

Bell, C. 1996, Time for Business, Report of the Small Business Deregulation Task Force, November.

Boyfield, K. 2007, RIAs: Why Don't They Work? A Submission to the Business Council for Britain, Centre for Policy Studies.

Department of the Treasury 2008, 'Regulation Impact Statement: Petrol Price Transparency and Competition'.

Hahn, R. 2005, In Defense of the Economic Analysis of Regulation, AIE-Brookings Joint Center for Regulatory Studies, Washington D.C.

2000, Reviving Regulatory Reform: A Global Perspective, AEI-Brookings Joint Center for Regulatory Studies, Washington D.C.

Hahn, R. and Tetlock, P. 2007 'Has Economic Analysis Improved Regulatory Decisions?' AIE-Brookings Joint Center for Regulatory Studies Working Paper 07-08.

Hahn, R., Burnett, J., Chan, Y., Mader, E. and Moyle, P. 2000 'Assessing the Quality of Regulatory Impact Analyses', AIE-Brookings Joint Center for Regulatory Studies Working Paper 00-01, January.

Industry Commission 1994, 'Developments in business regulation and its review', appendix G in Industry Commission Annual Report 1993-94. 
1995, Regulation and its Review: 1994-95,Commonwealth of Australia, September.

1997, Regulation and its Review: 1996-97,Commonwealth of Australia, October.

Jacob, K., Hertin, J., Hjerp, P., Radaelli, C., Meuwesse, A., Wolf, O., Pacchi, C. and Rennings, K. 2008, 'Improving the Practice of Impact Assessment' Evaluating Integrated Impact Assessments, Project no. 028889, $6^{\text {th }}$ Framework Programme.

Jacobs, S. 2006, 'Current Trends in Regulatory Impact Analysis: The Challenges of Mainstreaming RIA into Policy-making', Jacobs and Associates, May.

Jacobzone, S., Choi, C. and Miguet, C. 2007, 'Indicators of Regulatory Management Systems', OECD Working Papers on Public Governance, 2007/4, OECD Publishing.

Oakes, L. 2008, 'Rudd ignored FuelWatch price warnings', 28 May, at: http://news.ninemsn.com.au/article.aspx?id=570866

Office of Best Practice Regulation 2008, Best Practice Regulation Report 2007-08, Department of Finance and Deregulation, Canberra.

Parliament of Australia, House of Representatives 2009, Explanatory Memorandum for Excise Tariff Amendment (2009 Measures No. 1) Bill 2009 Customs Tariff Amendment (2009 Measures No. 1) Bill 2009. Available at: http://parlinfo.aph.gov.au/parlinfo/download/legislation/ems/ r4159_ems_7fbccee8-6e97-478b-822e-4edc9be2f9d9/upload_pdf/ 330974.pdf;fileType=application \%2Fpdf\#search=\%22alcopops \%22 2008, National FuelWatch (Empowering Consumers) Bill, 2008 National FuelWatch (Empowering Consumers) (Consequential Amendments) Bill 2008, Explanatory Memorandum.

Radaelli, C. and Meuwese, A. 2009, 'Better Regulation in the European Union. The political economy of impact assessment', in K. Jacob (ed.), Evaluating Integrated Impact Assessments (EVIA) Handbook, Springer (forthcoming).

Regulation Taskforce 2006, Rethinking Regulation: Report of the Taskforce on Reducing Regulatory Burdens on Business, Report to the Prime Minister and the Treasurer, Canberra, January.

Wilkinson, B. 2001, Constraining Government Regulation, New Zealand Business Roundtable. 